reducing stigmatisation, improving collaboration between professionals and implementing programmes for rehabilitation. Each speaker will give a short introductory presentation on their perspective on mental health in the workplace. This will be followed by a panel interview conducted by the session chair and include opportunity for questions to be asked from the audience.

IOSH research This session builds on recent research funded by IOSH into the 'Barriers and facilitators of return to work after sick leave in workers with common mental health disorders' (Joosen, et al). This study was completed in the Netherlands. Interviews were utilised to explore what occupational health professionals, mental health professionals, general practitioners, managers and workers saw as the barriers to and facilitators of work resumption by workers suffering from common mental disorders. The work includes reflection on the workers' own perspectives on what had led to sickness absence.

The research identified four main areas for improvement:

- The need for different agencies and professionals to collaborate more closely with each other when dealing with each case.

- Personalise workers' return to work support by focussing on their values, views and needs.

- Support workers in gaining self-awareness and regaining control.

- Improve manager's skills and knowledge in guiding workers after suffering a common mental disorder.

This research embellished IOSH's work in this area and is complimentary to its $\mathrm{OH}$ Toolkit, webinars and other information sources it has published. These tools are freely available and actively promoted to our members and wider audiences.

\section{A GLOBAL VIEW OF IMPACT OF PSYCHOSOCIAL FACTORS ON HEALTH, WORK AND WELLBEING}

Elia L Enriquez*. National Institute of Occupational and Environmental Health Mexico, Mexico City

\subsection{6/oemed-2018-ICOHabstracts. 1681}

Aim of special session Global Impact on productivity and health of psychological factors such as fatigue, depression, sleep deprivation in a company population

${ }^{1}$ Zorianna 1 Hyworon, Jorge A Morales-Camino MD, MS, PhD, FACOEM ${ }^{2}$

${ }^{1}$ InfoTech Inc. Winnipeg, Canada

${ }^{2}$ Medical Director of P and G Latin America, Mexico City, Mexico

\section{9a GLOBAL VIEW OF IMPACT OF PSYCHOSOCIAL FACTORS ON HEALTH, WORK AND WELLBEING}

ZL Hyworon. InfTech Inc. Winnipeg, Canada

\subsection{6/oemed-2018-ICOHabstracts. 1682}

Introduction Employers around the globe are being encouraged, recommended or legally mandated to consider the health of their employees beyond the scope of physical health. This broader scope of psychological health and safety in the workplace encompasses issues like depression, inadequate sleep, excessive job demands, low job satisfaction, extending their consideration into areas of direct and indirect business impact.

Methods Responses of 420000 employees in 123 countries to an online health risk appraisal that included measures of psychological and organisational factors were used to compare and correlate the impact of these factors, stratified by level of severity, on health and work. Psychosocial factors included work-related sources of personal stress, depression, sleep and organisational stress, the imbalance of job satisfaction and job stress. Impact on work was measured based on self-reported limitations on performance of work functions and absence from work.

Results As the severity of psychosocial risk factors increases, so does the unfavourable impact on job performance limitations and absenteeism, directly and indirectly, through the interaction with worsening physical health risk. For example, for individuals screened for depression (PHQ-9), comparing those with no depression symptoms to those with severe depression, we see globally 3.6 times the prevalence of individuals with 4 or more lifestyle-related risk factors, 13.0 times prevalence of 4 or more chronic conditions, 7.2 times prevalence of severe sleep problems and 11.5 times prevalence individuals reporting more stress than satisfaction from their work. Globally, prevalence of psychosocial risks varies by region, country and site. (e.g. prevalence of mild to severe depression ranges from $16 \%$ for North America to $37 \%$ for Asia and 39\% for Africa and Middle East.

Discussion When evaluating health risk, it is important to include psychosocial factors. More studies are required to investigate the impact of psychosocial factors on work and interaction between psychosocial factors and health.

\section{$1709 \mathrm{~b}$ EXPERIENCE OF THE IMPACT OF PSYCHOSOCIAL FACTORS IN A COMPANY IN SEVERAL COUNTRIES IN LATIN AMERICA REGION}

Jorge A Morales-Camino. Medical Director of P and G Latin America, Mexico City, Mexico

\subsection{6/oemed-2018-ICOHabstracts. 1683}

Introduction This work was conducted at a company of massive consuming products located in nine Latina-American countries. Total working population 12,235, male: 7,716, female: 4519 . $97 \%$ of population covered by On-Site Health Centres. Have 29 sites, 19 (65\%) with certified Wellness Program, covering $83 \%$ bof the working. $79 \%$ of the population participate in any of the site medical/Wellness programs. 32\% of the population completed the Health Risk Appraisal questionnaire called Wellness Check Point.

Methods From the 4564 employees who filled the HRA questionnaire out, it was calculated absenteeism, presenteeism, depression, level of stress and engagement (job stress vs job satisfaction). Rates of presenteeism and absenteeism were calculated for each of the variables (depression, stress and engagement). After that, the weighted average of the company Latin-American employee's salary was calculated. Having at the end the cost of each level variable was divided as follows: Depression (normal, with some symptoms, mild, moderate, severe); Stress (no risk, low moderate, high/very high); and engagement (much more satisfaction than stress, more satisfaction than stress, equal/neutral satisfaction than stress, more stress than satisfaction, much more stress than satisfaction). 